\section{UDC 665.64}

A. I. Shvachka, Cand. Sc. (Tech.), orcid.org/0000-0003-1076-6950,

Yu. K. Taranenko, Dr. Sc. (Tech.), Prof., orcid.org/0000-0003-4072-011X, O. Yu. Oliynik, Cand. Sc. (Tech.), Assoc. Prof., orcid.org/0000-0003-2666-3825,

Ye. V. Chernetskyi, Cand. Sc. (Tech.), Assoc. Prof., orcid.org/0000-0002-4197-7171

\section{DOI: $10.29202 /$ nvngu/2019-2/15}

State Higher Educational Institution "Ukrainian State University of Chemical Technology", Dnipro, Ukraine, e-mail: AleksandrShvachka@gmail.com; taranen@rambler. ru; oleinik_o@ukr.net; baksik_evgen@ukr.net

\title{
APPLICABILITY ANALYSIS OF THE LAPLACE INTEGRAL IN EVALUATING OUTPUT SIGNALS FOR AUTOMATIC SYSTEMS
}

Purpose. Solving a topical scientific problem of boosting the automatic system accuracy and performance by evaluating the Laplace integral using numerical methods to define transient characteristics in the context of alternating disturbance.

Methodology. Simulation and mathematical modeling methods, the Fourier and Laplace transform apparatus as well as mathematical statistics are at the core of the present research.

Findings. The influence of using the inverse Laplace integral resulted from numerical method calculations on the building accuracy of an automatic control system's transient characteristic was considered compared to the test dependency. Introducing the Laplace integral enables to implement the transition from the time domain to the frequency domain, and it positively affects the calculation accuracy as compared with the calculations that make use of the Fourier integral. The practicability of using the Laplace integral was proved for numerical transformation of transfer functions of the automatic control system components from the frequency to the time domain which could provide higher accuracy and performance of the system compared with the numerical calculations based on the Fourier integral.

Originality. Within the scope of the research, the use of the Laplace integral in the methods for numerical solving of differential equations of linear systems received solid scientific support, which enables to effectively evaluate the type of the transient characteristic in the course of the technological process and ensures its stability and quality improvement as the process load varies.

Practical value. The decrease in the resulting error rate for solving the differential equation of the system based on the inverse Laplace integral in relation to the test characteristic (the known table equation of the transient process characteristic according to the given research variant) as well as the stability of the transient characteristic of the system is shown. Therefore, as an applied aspect of using the resulting data obtained in the course of the research, we may consider the ability to further improve the principle of retrieving the transient characteristic of a control system. This creates a background of transferring the discovered technological solutions into the field of technical cybernetics.

Keywords: control system, Laplace integral, differential equation, transient characteristic

Introduction. Constant production growth of the high-quality target product as the amounts of natural and energy resources keep decreasing is a special feature of the modern information society. This defines the ever-growing requirements to the reliability and efficiency of the automatic control systems, both existing ones and those being designed [1].

The wealth of theoretical knowledge in the field of chemical technological process organization as well as constant improvement and development of the objectoriented computer programming allows using mathematical modeling to solve problems in the field of the system analysis and synthesis. With that said, not only must the developer pay attention to the technical and mechanical aspects of the equipment, but also to the functional characteristics of distinct dynamic channels which ensure functioning of the whole system to a satisfactory degree (Fig. 1).

All possible states of the displayed system that automatically controls the process can be described by the following system of differential equations [2]

(c) Shvachka A. I., Taranenko Yu. K., Oliynik O. Yu., Chernetskyi Ye. V., 2019

$$
\begin{gathered}
a_{0} \frac{d^{n} y(t)}{d t^{n}}+a_{1} \frac{d^{n-1} y(t)}{d t^{n-1}}+\ldots+a_{n} y(t)= \\
=b_{0} \frac{d^{m} u(t)}{d t^{m}}+b_{1} \frac{d^{m-1} u(t)}{d t^{m-1}}+\ldots+b_{m} u(t)+c_{0} f(t),
\end{gathered}
$$

where $a_{i}, b_{j}, c_{o}$ are equation coefficients defined by the object's nature.

To evaluate the control process, it is required to solve the differential equation as in (1). The initial limitations defined by the combination of the output variable and its derivatives should be taken into account. Moreover, the transient process in the system can occur during a scheduled action or disturbance. The resulting transient process defined by solving the initial differential equation contains the sum of two components

$$
y(t)=y_{r e}(t)+y_{\text {fre }}(t),
$$

where $y_{r e}(t)$ is a required component which represents a particular solution of a non-homogenous differential equation (1) that has the right-hand side; $y_{f r e}(t)$ is a free component which represents the general solution of a homogenous initial differential equation with no right-hand side. 


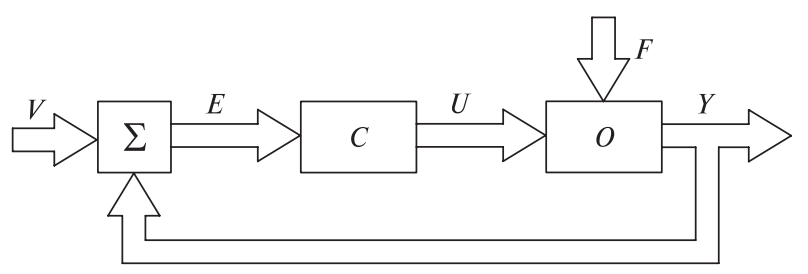

Fig. 1. The structure of the system:

$C$ - controller; $O-$ object; $U$ - control; $F$ - disturbance; $Y$ - process indicator; $E$ - control errors; $V$ - task

The free component is defined by the internal characteristics of the system whereas the required component characterizes the system state after the external action was applied.

To ensure the efficiency of the control system, it is required to test its stability against the declared quality values in accordance with the process adjustment curve. Modern systems must include both elements and organized links between them that are immune to disturbance. This is the robustness of the system. The invariance requirement, i.e. the invulnerability of the process output values to external factors, should also be taken into account.

There are a number of methods to solve differential equations. The most commonly used one includes the following steps:

1) finding the general solution of the homogenous equation;

2) finding the particular solution of the non-homogenous equation;

3) finding the general solution of the non-homogenous differential equation.

The form of the differential equation does not grant a clear vision of the dynamic characteristics of the system; however, the transient process of the system from one stable state to another defined by solving the differential equation could reveal the opportunity for such a vision.

In order to evaluate the dynamics of different systems, they have to be adjusted to the same initial conditions; input actions of the same type should also be applied to each one of them. Otherwise, the very same differential equation can have a multitude of solutions that define the transient process, each of which is determined by its own initial conditions as well as the input action type. The solution for such a situation was to zero out the initial conditions of the considered systems when performing typical actions such as steps, impulses, harmonics. The reaction to the first action of the list is a transient process $h(t)$ [3] which defines the dynamic characteristics of the system.

As a rule, in theoretical research analytical methods for the output signal of the control system are used. They are based upon classical methods for solving differential equations, and they have a limited use in practice.

In practical calculations of system signals, models that are based on the operational form of the initial differential equation have proved themselves to be quite efficient. Operation calculations based on the Laplace in- tegral define the justness of algebraic actions upon the operator expressions of the differential equations. They also establish conditions under which they become feasible. Using the Laplace integral enables to carry out the operation analysis of the system which was reset to its initial values, with typical input actions applied. Besides, this allows establishing an arbitrary set of initial actions and limitations.

The expanding use of the Laplace integral for an operator entry form of a differential equation system is connected with its ability to simplify computational operations as well as the ability to choose the frequency over the time domain. This factor is quite significant due to the fact that today frequency-based methods are a solid foundation for engineering analysis of automatic control systems. Using object-oriented programming provides the opportunity to intensify operation calculations to evaluate optimal parameters of an automatic control system for control analysis as well as key channels of performing disturbance actions in the course of the technological process.

Analysis of the recent research and publications. An automatic control system shall be considered as a dynamic self-contained system that has multiple degrees of freedom. Disturbance of both internal and external types is constantly affecting the system, and the result of it is the fact that the system operates in dynamic modes that lack stability. Today, most commonly used approaches to solve the equation of an automatic control system to evaluate its adjustment characteristic are [2]:

- classical approaches;

- graph-analytic or frequency methods;

- operation methods;

- numerical methods.

The classical approach to solving the system's differential equation takes into consideration the physical nature of the processes. This is a well-studied and widely used approach; however, in practice it is characterized by a number of flaws, some of those are:

- the need to carry out complex operations of differentiation and integration that in their turn require special knowledge, as well as the need to solve particular differential equations;

- the difficulty of defining proper integration coefficients for the provided initial data in actual operating conditions.

The operation methods are implemented by the use of the Fourier, Heaviside, and Laplace integrals [3]. Such an approach greatly simplifies mathematical calculations due to the fact that in the process of finding the integration coefficients algebraic equations are used. With that said, there is no need to implement the complex procedure of defining the integration coefficients, and that poses a distinct advantage of the method. The key difficulty of the operation method in practice is performing sophisticated transformations of the functions back to their originals and forth.

The graph-analytical approach is based on the links between transient and frequency characteristics of the automatic control system. Taking into account the relations between the Laplace and Fourier integrals, the fre- 
quency method can be considered as a frequency analogue of the above reviewed operation method. A special feature of the graph-analytical method is its descriptiveness, the ability to interpret the characteristics of the automatic control system that were obtained experimentally.

The wide use of numerical methods is connected with the appearance of problem-oriented programming tools and instrumental systems [4]. In such systems, the entire process of the mathematical model machine implementation is embodied in its initial state at the structural level without the loss of the object's physical nature. The increase in the personal computer performance as well as the introduction of the interactive graphical user interface has significantly improved the development of numerical methods.

The analysis of text sources has revealed that in numerical methods the Laplace integral is widely used.

The modified Laplace homotopic perturbation method (MLT-HPM) [5] ensures the accuracy increase for approximate solutions resulted from using the Laplace transform homotopic perturbation (LT-HPM) and other methods. However, in the described method it is necessary to include first-order approximations (MLT-HPM), as opposed to LT-HPM, which requires performing a greater number of iterations for the same research. In the research [6] it is shown that both forward and reverse heat conductivity problems in real time can be solved without addressing the inverse Laplace integral. Instead, recursive ratios connected with Pade digital filters may be used. In the scientific work [7] dedicated to the electromagnetic research of transient processes the authors prove the viability of using the Laplace integral in the numerical form. To check the resulting data, it is recommended to carry out a prototype experiment. The authors of the article [8] searched for a suitable algorithm that could be used to solve elastodynamic problems efficiently and accurately. In particular, the following algorithms were tested: Gaver-Stehfest, Rho Gaver-Wynn, FixedTalbot, FFT, as well as the declared instrumental environment, Maple 16, to conduct the research.

Summing up the reviews of the literature sources, we can note that currently in the scientific society there is no distinct unity on styles and ways of implementing the numerical form of the Laplace integral as applied to objects of various physical nature. In connection with that it can be concluded that solving the Laplace integral in the numerical form as well as its implementation with the help of widely accessible tools for the purpose of actively using it in automatic control theory poses an actual scientific problem.

Objectives of the article. A solution of an actual scientific problem of increasing the accuracy and performance of an automatic control system by means of numerical evaluation of the Laplace integral to define transient characteristics in conditions of alternating perturbance.

To fulfill the designated goal, it is required to solve the following problems:

- to choose an instrumental research environment for the inverse Laplace integral in order to solve prob- lems of analysis and synthesis in the theory of automatic control systems, give reasons in support of the choice;

- to evaluate the numerical method accuracy of the inverse Laplace integral in relation to typical objects of an automatic control system as well as to form recommendations on the machine implementation;

- to develop and research the simulation model that connects the original function and its image in order to compare the Laplacian and Fourier methods and proves the stability of the Laplace integral characteristics.

Choosing the right tools. The rapid advancement of personal computers defines a constant change in requirements to programming languages. Higher $\mathrm{CPU}$ frequencies allow providing required computation performance which favors the use of interpreted programming languages. The priority of compiled programming languages as related to interpreted languages is in outputting a high-performance code. Taking into account the computation power of today's computers, the code performance is no longer a limiting factor, thus it makes sense to use simpler and more flexible tools such as interpreted programming languages in the development process. Taking into account the above said, for the development environment the high-level Python programming language was chosen [9].

Up till recently, the Python library had been lacking components that could implement numerical operations to transform elements of control systems from the time domain into the frequency one. That was the reason for using the inverse Fourier integral in building technical systems. Implementing the (invertlaplace) algorithm that can be found in the (mpmath) module of the Python language solves this problem by providing accurate solutions for real and complex variables.

Simulation modeling of a transient characteristic of an object and regulator with the use of numerical methods of the Python environment. A shell tube heat exchanger was chosen as a typical technological controlled object. The transfer function of the object, changing over to the Laplace integral, is defined at the level of the "heated object temperature - heat transfer agent" channel by a consequential connection of three first-order aperiodic links and a delay link as in the following

$$
W_{o}(s)=\frac{k_{o}}{\left(T_{1} s+1\right) \cdot\left(T_{2} s+1\right) \cdot\left(T_{3} s+1\right)} \cdot e^{-\tau_{o} s},
$$

where $k_{o}$ is the object amplification coefficient; $T_{i}$ is time constant of the $i^{\text {th }}$ link, $\mathrm{s}$; $\tau_{o}$ is object delay time, $\mathrm{s} ; s$ is the complex variable that matches the expression

$$
s=\sigma_{0}+j \omega,
$$

where $\sigma_{0}$ is $x$-coordinate of the absolute convergence; $j$ is the imaginary unit, $j=\sqrt{-1}$; $\omega$ is frequency, $\mathrm{rad} / \mathrm{s}$.

In accordance with the transfer $(W(s))$ and transient $(h(t))$ function link equation, performing the inverse Laplace integration $\left(\mathrm{L}^{-1}\right)$, the result will equal [2]

$$
h(t)=L^{-1}\left[W(s) \cdot \frac{1}{s}\right]
$$


Based on the dependency (5), a Python-based algorithm was developed, a snippet of which is displayed below:

def run_invertlaplace $(t, f p, t a u)$ :

$y=[]$

for $i$ in np.arange $(0$, len $(t))$ :

if $t$ [i] $<=$ tau:

y.append $(0)$

else: $y$.append(invertlaplace $(f p, t[i]$, method ='talbot')) return $y$

$t=n p$.arange $(0,100,0.05)$

$T 1=5 ; T 2=4 ; T 3=4 ; K=1.5$

tau $=14$

$f p=$ lambda $p: K^{*} \exp (-\operatorname{tau} * p) /((T 1 * p+1) *(T 2 * p+$

$+1) *(T 3 * p+1) * p)$

$y=n p . \operatorname{array}($ run_invertlaplace $(t, f p, t a u))$

$y \max =\max (y)$

$\operatorname{tau} 1=7$

fp $1=$ lambda $p: K * \exp (-\operatorname{tau} 1 * p) /((T 1 * p+1) *(T 2 *$

$* p+1) *(T 3 * p+1) * p)$

$y 1=n p . \operatorname{array}($ run_invertlaplace $(t, f p 1$, tau 1$))$

$y \max 1=\max (y 1)$

plt.title(, The mentioned transient characteristics $\backslash n$ result-

ing from invertlaplace execution")

plt.plot $\left(t, y / y \max\right.$, linewidth $=1$, label $={ }^{\prime}$ tau $\left.=14^{`}\right)$.

A variant of calculation for the given transient characteristic of a technological controlled object with different values of the adjustment parameter ( $t a u)$ values is shown in Fig. 2

The resulting characteristic displays the presence of a delay, defined among other reasons by the containers, as well as the presence of self-improvement when the external action is absent.

The transfer function of the proportional - integral - differential regulator (PID) used in the system has a parallel structure

$$
W_{c}(s)=\left(1+\frac{k_{d} \cdot T_{d} \cdot s}{1+T_{d} \cdot s}\right) \cdot k_{p} \cdot\left(1+\frac{1}{T_{i} s}\right),
$$

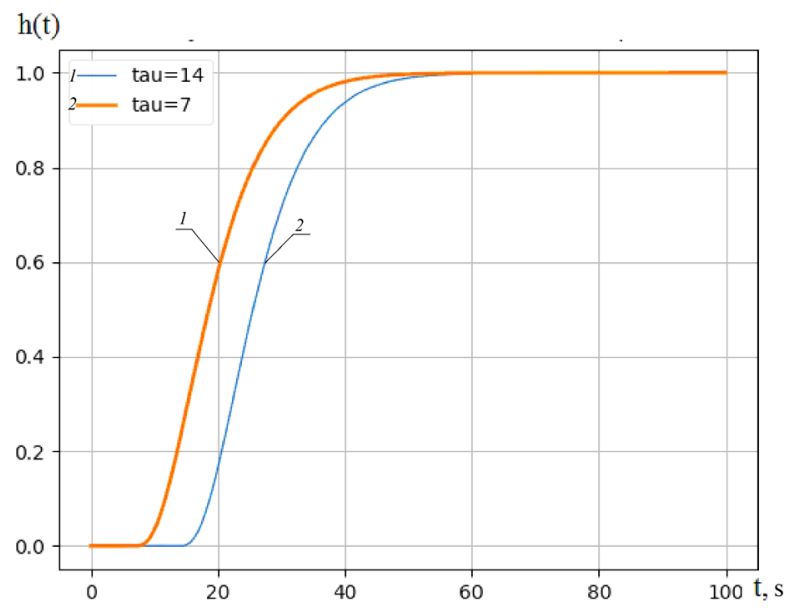

Fig. 2. Transient characteristic of a triple-container controlled object in varying the (tau) delay value (numerical method of the Python programming environment) where $T_{i}$ is the integration time constant value, $\mathrm{s} ; T_{d}$ is the differentiation time constant value, $\mathrm{s} ; k_{p}$ is the P-link amplification coefficient value; $k_{d}$ is the D-link amplification coefficient value.

Therefore, the transfer function in the presented form contains a filter ( $f$ ) that reduces the influence of the highfrequency component of the signal which can be amplified as a result of introducing the differential component

$$
W_{f}(s)=\frac{k_{d}}{T_{d} \cdot s+1} .
$$

A snippet of the subroutine code for the transient characteristic of the regulator is displayed below:

$K p=2 ; T i=2 ; K d=4 ; T d=0.5$

$f p=l a m b d a p:$

$\left(1+\left(K d^{*} T d^{*} p\right) /\left(1+T d^{*} p\right)\right) * K p *(1+1 /(T i * p)) *$

* $(1 / p)$

$y=$ [invertlaplace $(f p, t t[i]$, method $=$ 'talbot') for $i$ in $n p$. $\operatorname{arange}(0, \operatorname{len}(t t))]$

$K d=0$

$f p=$ lambda $p$ :

$\left(1+\left(K d^{*} T d^{*} p\right) /\left(1+T d^{*} p\right)\right) * K p *\left(1+1 /\left(T i^{*} p\right)\right) *$ * $(1 / p)$

$y 1=$ [invertlaplace $(f p, t t[i]$, method $=$ 'talbot' $)$ for $i$ in $n p$.arange $(0$, len $(t t))]$

$T d=100 ; K p=1$

$f p=$ lambda $p:(K d *(1+T d * p))$

y2 $=$ [invertlaplace $(f p, t t[i]$, method $=$ 'talbot') for $i$ in np.arange $(0, \operatorname{len}(t t))]$

plt.title(, Transient characteristics of the regulators $\backslash n$ resulting from invertlaplace execution,).

The graphic form of the result in the shape of transient characteristics (PI PD, PID) meets the fundamentals of the classical control theory, namely consequential triggering of the proportional (system performance), differential (anticipation signal), and integral components (static accuracy).

To perform transition to the PI regulator, the differential component was disabled (the amplification coef-

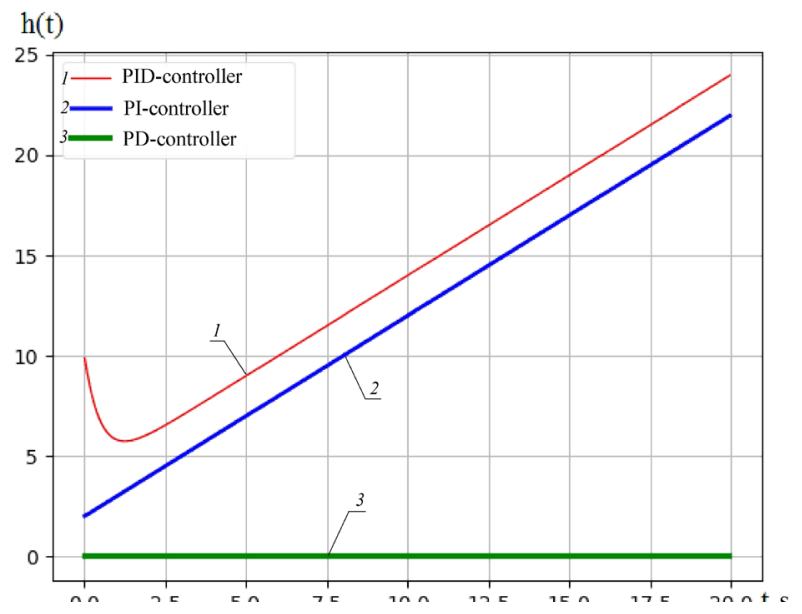

Fig. 3. Transient characteristic of PI, PD, PID regulators (numerical method of the Python programming environment) 
ficient of the differentiator was set to the zero value). The absence of an efficient anticipation action has led to a delay in the control channel.

The collected statistical data at the research stage claims that in the numerical method of the inverse Laplace integral the approximation of the $x$-coordinate of absolute divergence to the origin must be performed to ensure a larger period of time. With that in mind, the calculation result can be considered unsatisfactory if the $\mathrm{X}$-coordinate moves to the left of the right boundary in the Laplace integral range.

Research on accuracy rate for the inverse Laplace integral in control theory problems. Let us prove the viability of using the numerical method of the inverse integral as applied to objects with inertia and time lag alongside the regulator with the PID control law, which are chosen as typical elements of production process objects. It is necessary to evaluate the accuracy of the given numerical method in solving problems of this class.

In this case the transfer function of the regulator as displayed in (6) has an accurate table transformation value [10] which corresponds to the dependency.

In this case the transfer function of the regulator as displayed in (6) has an accurate table transformation value [10] which corresponds to the dependency

$$
h(t)=\frac{k_{n}}{T_{u}} \cdot\left(T_{u}+k_{d} \cdot T_{d}\right)+\frac{k_{n}}{T_{u}} \cdot t+k_{d} \cdot\left(T_{u}-T_{d}\right) \cdot \exp \left(\frac{-t}{T_{d}}\right) .
$$

With the use of the Python programming language it became possible to evaluate the truthfulness of an instrumental calculation of the inverse Laplace integral in comparison with the test function according to the equation (8). The quantitative evaluation of accuracy is the absolute error of the evaluation results (Fig. 4). The graphical data support the evidence that the error of the developed evaluation model does not exceed $\left(2.0 \cdot 10^{-14}\right)$. It was experimentally proved that the error value of this method may vary in both directions. By changing the (mp.pdps) values and the $\mathrm{tt}[\mathrm{i}+1]-\mathrm{tt}[\mathrm{i}]$ step, the variable values were defined.

The evaluated accuracy data of the inverse Laplace integral in the Python environment clearly display great

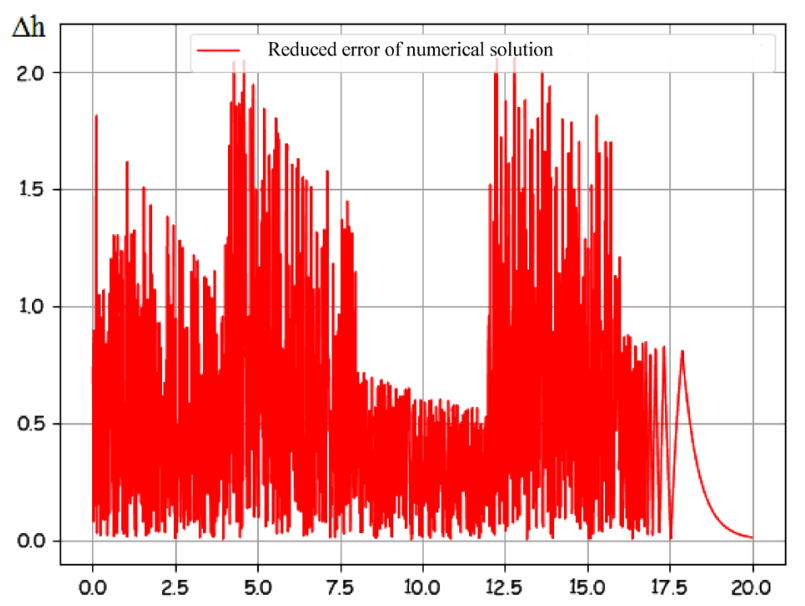

Fig. 4. The error value of the numerical solution by using the Laplacian method $\left(\cdot 10^{-14}\right)$ viability for using the integral in solving problems of analysis and synthesis of control systems. The validity of this conclusion has yet to be supported by comparing the modeling results of the Fourier integral-based numeric method for the same class of problems.

According to the known theoretical data of the classical automatic control theory [2], there is a connection between the original function and its image in the inverse Fourier integral as follows

$$
x(t)=\frac{1}{2 \pi} \cdot \int_{-\infty}^{+\infty} X(j \omega) \cdot e^{j \omega \cdot t} d \omega .
$$

Taking into account the dependency, the transient characteristic $(h(t))$ of a self-contained system is connected with its real frequency response $(\operatorname{Re}(\mathrm{W}(\mathrm{j} \omega)))$ via the following expression

$$
h(t)=y=\frac{2}{\pi} \cdot \int_{0}^{+\infty} \operatorname{Re}(W(j \omega)) \cdot \frac{\sin (\omega t)}{\omega} d \omega .
$$

Along with that, for the equation (10) it is necessary to evaluate the slice frequency, which allows the real frequency response module of the self-contained system to drop down to a negligibly small value, and never exceed the desired range values even if the frequency increases in the future. Based on these values, we specify the integration limit in the Fourier integral. For that we will use the numerical method of searching the inverse Fourier integral for the transfer function of an object as shown in (3):

def invertfure (w,tau):

$j=(-1) * * 0.5$

return $\left(\left(K^{*} n p \cdot \exp (-\operatorname{tau} * j * w) /((T 1 * j * w+1) *(T 2 *\right.\right.$

$* j * w+1) *(T 3 * j * w+1)))$.real)

tau $=14$

$z=$ [invertfure $(w$, tau $)$ for $w$ in $w w]$

tau $=7$

$z 1=$ [invertfure $(w$, tau $)$ for $w$ in $w w]$

plt.title('Dependency of the real part of the transfer function $\backslash n$ of the controlled object $\operatorname{Re}(W(j * w))$ on the frequency ').

Plotting a real frequency response based on the evaluation results allows stepping into the frequency domain. Let us define the integration limit by the attenuation intensity (Fig. 5).

The real frequency response analysis of a controlled object (Fig. 5) allows drawing conclusions on defining the Fourier function integration range. The lower limit is set at zero. The pointer at 0.6 sets the upper limit due to the fact that as the frequency grows further, the overregulation is equal to zero, and the value of real part of the frequency response is constant and equal to zero. Taking into account the resulting values and switching to the operation of numerical integration in (9), we get the target transient characteristic with the use of the inverse Fourier integral method (Fig. 6).

Therefore, transient characteristics are evaluated on the basis of the Laplace and Fourier integrals. For the efficacy of the representability criteria, an exact table ex- 


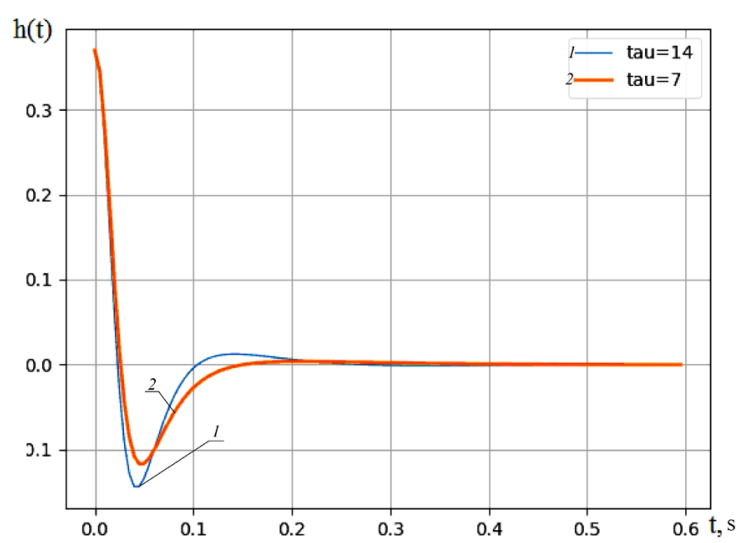

Fig. 5. Real frequency response when switching to the Fourier with the varying delay value of (tau) (numerical method of the Python programming environment)

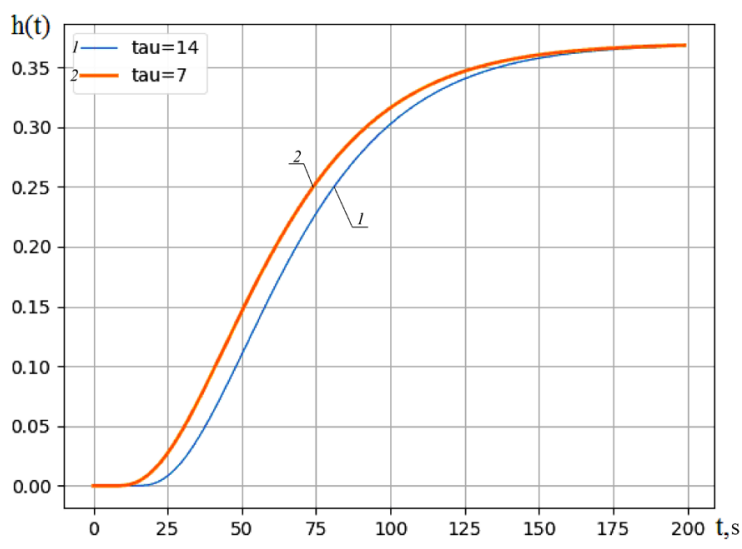

Fig. 6. Transient response of the controlled object with the use of the inverse Fourier integral with the varying delay value of (tau) (numerical method of the Python programming environment)

pression value was taken [2] as the test function at the research stage

$$
\begin{aligned}
& h(t)=k \frac{-1}{\left(T_{1}-T_{3}\right)\left(T_{1}-T_{2}\right)} T_{1}^{2} \cdot \exp \left(\frac{\tau-T}{T_{1}}\right)+ \\
& +k \frac{1}{\left(T_{1}-T_{2}\right)\left(T_{2}-T_{3}\right)} T_{2}^{2} \cdot \exp \left(\frac{\tau-T}{T_{2}}\right)+ \\
& +k \frac{-1}{\left(T_{1}-T_{3}\right)\left(T_{2}-T_{3}\right)} T_{3}^{2} \cdot \exp \left(\frac{\tau-t}{T_{3}}\right)+k .
\end{aligned}
$$

Let us perform alternating subtraction of the instrumental method value and the test function. We will observe a characteristic as shown in (Fig. 7).

The results of the comparative analysis (Fig. 7) reveal that the deviation of the evaluation results for the Fourier integral data in relation to the table test function values alter in the increasing and then descending oscillating forms.

In this regard, the results of plotting the transient characteristic based on the Laplace integral are quite remarkable as they are identical to the test function.

Thus, it should be firmly asserted that the stability and accuracy increase in the transient characteristic

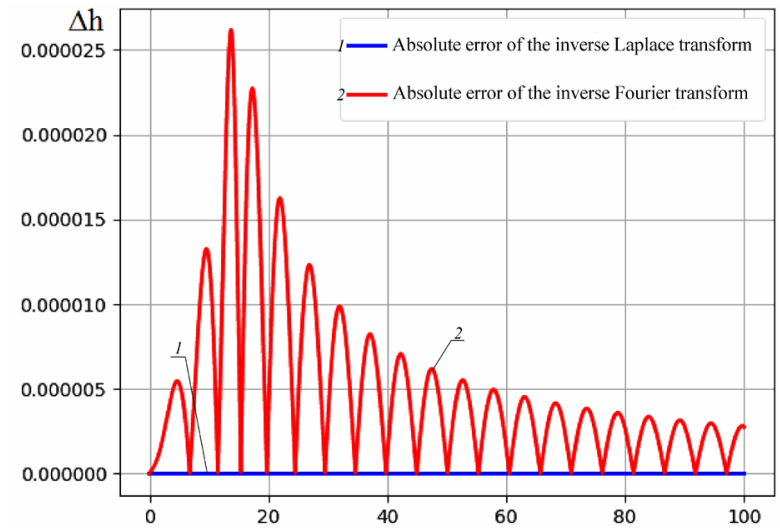

Fig. 7. Comparative accuracy characteristics of the evaluation results for the inverse Laplace and Fourier integrals

based on the inverse Laplace integral was fully proved. The shown characteristics are crucial for modern production process objects in increasing the single capacity and reactivity of an equipment.

Conclusion. The research solves the topical technical-scientific problem of increasing the accuracy and performance of an automatic system which meets the requirements of functioning in conditions of altering disturbance, based on the synthesis of computer modeled results of the numerical methods for the inverse Laplace integral and the methodology of the computational experiment. The research and methodological base of operational analysis was further developed in the field of switching from the frequency to the time domains.

1. For the first time, a method of the inverse Laplace integral for the numerical method analysis of dynamics for automatic systems in the Python programming environment was developed, which allowed increasing the efficacy of decision making in altering disturbance conditions. Also, the need to shift the $\mathrm{x}$-coordinate towards the coordinate origin in the numerical method for larger time amounts and getting correct results was ascertained.

2. Key trends as well as a quantitative evaluation of the numerical method error in regard to typical objects with delay, inertia, and PID law implementation that does not exceed $3.0 \cdot 10^{-5}$ were established. By lowering the search step, it is possible to increase the quality which in its turn determines the increase in computation efficacy.

3. The stability of the characteristics as well as the increase in the accuracy values while building Laplace integral based transient processes for control systems was proved. The comparative experiment carried out as a result of numerical modeling based on the Fourier integral showed unsatisfactory divergence of the latter in regard to the test function.

\section{References.}

1. Nikolsky, V., Oliynyk, O., Shvachka, A. and Nachovny, I., 2017. Thermal treatment of concentrated liquid toxic waste and automatic control of process efficiency. Eastern-European Journal of Enterprise Technologies. 
Ecology, 5/10(89), pp. 26-31. DOI: 10.15587/17294061.2017.111846.

2. Kamenskii, S., 2017. Systems of automatic control, mechatronics and robotics: monograph. Novosibirsk: NSTU Publishing House.

3. Kim, D., 2014. Algebraic methods for the synthesis of automatic control systems: monograph. Moscow: FIZMATLIT.

4. Dovhopolyi, Ya., Manko, G., Trishkin, V. and Shvachka, A., 2017. Development of the program for selftuning a proportal-integral-differential controller with an additional controlling action. Eastern-European Journal of Enterprise Technologies. Information technology. Industry control systems, 6/2(90), pp. 61-66. DOI: 10.15587/1729-4061.2017.114333.

5. Filobello-Nino, U., Vazquez-Leal, H., SarmientoReyes, A., Cervantes-Perez, J., Perez-Sesma, A., Jimenez-Fernandez, V., Pereyra-Diaz, D., Huerta-Chua, J., Morales-Mendoza, L., Gonzalez-Lee, M. and CastroGonzaleza, F., 2017. Laplace transform-homotopy perturbation method with arbitrary initial approximation and residual error cancellation. Applied Mathematical Modelling, 41, pp. 180-194. DOI: 10.1007/s40314-0130073-z.

6. Lotfi, M., Mezrigui, L. and Heyd, R., 2016. Study of heat conduction through a self-heated composite cylinder by Laplace transfer functions. Applied Mathematical Modelling, 40, pp. 10360-10376. DOI: 10.1016/ J.APM.2016.07.012.

7. Uribe-CamposFelipe, A., 2014. Laplace Synthesis Validation through Measurements on Underground Transmission Cables. Ingeniería, Investigación y Tecnología, 15, pp. 575-584. DOI: 10.1016/S1405-7743(14)70655-9.

8. Adamek, V., Vales, F. and Cerv, J., 2017. Numerical Laplace inversion in problems of elastodynamics: Comparison of four algorithms. Advances in Engineering Software, 113, pp. 120-129. DOI: 10.1016/j.advengsoft.2016.10.006.

9. Linge, S. and Langtangen, H., 2016. Programming for Computations - Python: A Gentle Introduction to Numerical Simulations with Python. Switzerland: Springer International Publishing.

10. Lubentsova, E., 2014. Control systems with dynamic structure choice, fuzzy logics and neural network models. Stavropol: SKFU.

\section{Аналіз застосовності інтеграла Лапласа в розрахунках вихідних сигналів автоматичних систем}

\section{О. І. Швачка, Ю. К. Тараненко, О. Ю. Олійник, Є.В. Чернецький}

Державний вищий навчальний заклад „Український державний хіміко-технологічний університет“, м. Дніпро, Україна, e-mail: AleksandrShvachka@gmail.com; taranen@ rambler.ru; oleinik_o@ukr.net; baksik_evgen@ukr.net

Мета. Рішення актуальної наукової задачі підвищення точності та швидкодії автоматичної системи шляхом оцінки інтеграла Лапласа чисельни- ми методами для визначення перехідних характеристик в умовах змінних збурень.

Методика. В основі проведеного дослідження лежать методи імітаційного й математичного моделювання, апарат інтегральних перетворень Лапласа та Фур'є, а також математичної статистики.

Результати. Розглянуто вплив використання інверсії інтеграла Лапласа, отриманого в розрахунках за чисельним методом, у порівнянні з тестовою залежністю на точність побудови перехідної характеристики АСУ. Уведення інтеграла Лапласа дозволяє виконати перехід із тимчасової області до частотної та суттєво впливає на точність побудови на відміну від розрахунків при використанні інтеграла Фур'є. Доведена доцільність використання інтеграла Лапласа для чисельного перетворення передавальних функцій компонентів АСУ з області частот у тимчасову область, що забезпечувало би підвищення точності, швидкодії системи в порівнянні $з$ чисельним розрахунком інтеграла Фур'є.

Наукова новизна. У рамках дослідження обгрунтовано й доведено використання інверсії інтеграла Лапласа в методах чисельного рішення диференціальних рівнянь лінійних систем, що дозволяє оцінити вид перехідної характеристики в темпі ходу технологічного процесу й забезпечує її стабільність і підвищення якості при зміні навантаження на процес.

Практична значимість. Показано зниження похибки результатів рішення диференціального рівняння лінійної системи на підставі інверсії інтеграла Лапласа по відношенню до тестової характеристики (відоме табличне рівняння характеристики перехідного процесу за цим варіантом дослідження), а також стабільність перехідної характеристики системи. Отже, прикладним аспектом використання отриманого результату наукового дослідження $є$ можливість удосконалення принципу отримання перехідної характеристики керуючої системи. Це становить передумови трансферу на практиці отриманих технологічних рішень в області технічної кібернетики.

Ключові слова: система управління, інтеграл Лапласа, диференціальне рівняння, перехідна характеристика

\section{Анализ применимости интеграла Лапласа в расчетах выходных сигналов автоматических систем}

\author{
А. И. Швачка, Ю. К. Тараненко, О. Ю. Олейник, \\ Е.В. Чернецкий
}

Государственное высшее учебное заведение „Украинский государственный химико-технологический университет“, г. Днепр, Украина, e-mail: AleksandrShvachka@ gmail.com; taranen@rambler.ru; oleinik_o@ukr.net; baksik_ evgen@ukr.net

Цель. Решение актуальной научной задачи повышения точности и быстродействия автоматической системы путем оценки интеграла Лапласа 
численными методами для определения переходных характеристик в условиях переменных возмущений.

Методика. В основе проведенного исследования лежат методы имитационного и математического моделирования, аппарат интегральных преобразований Лапласа и Фурье, а также математической статистики.

Результаты. Рассмотрено влияние использование инверсии интеграла Лапласа, полученного в расчетах по численному методу, в сравнении с тестовой зависимостью на точность построения переходной характеристики АСУ. Введение интеграла Лапласа позволяет выполнить переход из временной области в частотную и существенно влияет на точность построения в отличие от расчетов при использовании интеграла Фурье. Доказана целесообразность использования интеграла Лапласа для численного преобразования передаточных функций компонентов АСУ из области частот во временную область, что обеспечивало бы повышение точности, быстродействия системы по сравнению с численным расчетом интеграла Фурье.

Научная новизна. В рамках исследования обосновано и доказано использование инверсии интеграла Лапласа в методах численного решении дифференциальных уравнений линейных систем, по- зволяющем оценить вид переходной характеристики в темпе хода технологического процесса и обеспечивающим ее стабильность и повышение качества при изменении нагрузки на процесс.

Практическая значимость. Показано снижение погрешности результатов решения дифференциального уравнения линейного системы на основании инверсии интеграла Лапласа по отношению к тестовой характеристике (известное табличное уравнение характеристики переходного процесса по данному варианту исследования), а также стабильность переходной характеристики системы. Следовательно, прикладным аспектом использования полученного результата научного исследования является возможность совершенствования принципа получения переходной характеристики управляющей системы. Это составляет предпосылки трансфера на практике полученных технологических решений в области технической кибернетики.

Ключевые слова: система управления, интеграл Лапласа, дифференциальное уравнение, переходная характеристика

Рекомендовано до публікації докт. техн. наук Д.Г.Зеленцовим. Дата надходження рукопису 23.01.18. 